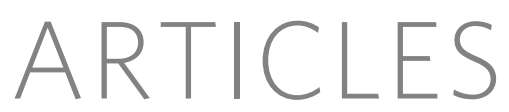

\title{
Ventastega curonica and the origin of tetrapod morphology
}

\author{
Per E. Ahlberg ${ }^{1}$, Jennifer A. Clack ${ }^{2}$, Ervīns Lukševičs ${ }^{3}$, Henning Blom ${ }^{1}$ \& Ivars Zupiňš ${ }^{4}$
}

\begin{abstract}
The gap in our understanding of the evolutionary transition from fish to tetrapod is beginning to close thanks to the discovery of new intermediate forms such as Tiktaalik roseae. Here we narrow it further by presenting the skull, exceptionally preserved braincase, shoulder girdle and partial pelvis of Ventastega curonica from the Late Devonian of Latvia, a transitional intermediate form between the 'elpistostegids' Panderichthys and Tiktaalik and the Devonian tetrapods (limbed vertebrates) Acanthostega and Ichthyostega. Ventastega is the most primitive Devonian tetrapod represented by extensive remains, and casts light on a part of the phylogeny otherwise only represented by fragmentary taxa: it illuminates the origin of principal tetrapod structures and the extent of morphological diversity among the transitional forms.
\end{abstract}

The fossil record of Devonian tetrapods, the earliest and most primitive limb-bearing members of the tetrapod stem group, was for many decades restricted to the iconic 'four-legged fish' Ichthyostega from the Famennian (latest Devonian) of Greenland ${ }^{1-5}$ and the fragmentary genus Acanthostega from the same strata ${ }^{2}$. During the last 20 years, intense collecting and research has produced complete skeletal material of Acanthostega ${ }^{6-8}$ and a series of new taxa, greatly expanding the temporal and geographical range of these animals. Devonian tetrapods are now known from as early as the late Frasnian, the earlier part of the Late Devonian period, and have been recorded from Gondwana and north China as well as Laurussia ${ }^{9-18}$. However, most of these new forms remain very poorly known, typically represented by no more than lower jaw rami or isolated postcranial bones; Acanthostega and Ichthyostega are still the only Devonian tetrapods known from near-complete skeletons. We know less about the fishtetrapod transition than the taxic diversity suggests.

Among the more fragmentary forms are five (Metaxygnathus, Densignathus, Elginerpeton, Obruchevichthys and Ventastega) that combine a characteristically tetrapod lower-jaw morphology with the retention of coronoid fangs and other 'fish' characters absent in Acanthostega, Ichthyostega and more crownward limbed members of the tetrapod stem group ${ }^{19,20}$. These genera seem to fall into the morphological gap between Acanthostega and Ichthyostega and the (paraphyletic) elpistostegids, but all except Ventastega are very incomplete. Ventastega was originally described in 1994 from the Pavāri locality in the late Famennian Ketleri Formation of Kurzeme, western Latvia ${ }^{21}$ (Supplementary Information 1). Further excavations at this site up to 2001 have yielded an extensive body of material, including previously unknown or incompletely known elements such as a near-complete skull roof plus braincase and associated cheek (Fig. 1), scapulocoracoid, anocleithrum, interclavicle and ilium (Fig. 2). All come from a single horizon, and the occurrence of multiple identical examples of several elements (jaws, cheek plates, maxillae, clavicles, cleithra, nasals) indicates that only one tetrapod taxon is present. The new material allows us to reconstruct the whole skull except the basioccipital-exoccipital complex for the first time, as well as most of the shoulder girdle and part of the pelvis (Fig. 3). It also permits a more robust phylogenetic analysis of Ventastega, confirming its position below Acanthostega in the tetrapod stem group. Ventastega thus provides the first detailed picture of a Devonian tetrapod more primitive than Acanthostega.

\section{The skull}

The overall skull shape is characteristically 'early tetrapod' with a spade-shaped snout and large dorsally positioned orbits (Figs 1 and $3 \mathrm{a}-\mathrm{d})$. However, its proportions resemble more closely those of Tiktaalik ${ }^{22}$ than do the skulls of Ichthyostega ${ }^{3}$ and Acanthostega ${ }^{8}$, as shown both by visual comparison (Fig. 4a-c) and morphometric analysis (Fig. 4e, f and Supplementary Information 2). Furthermore, the conservation of morphological landmarks such as notches and projections of the skull-table margin is almost perfect between Tiktaalik and Ventastega, showing that the two differ only in proportions, whereas Acanthostega and Ichthyostega lack many of the landmarks. One landmark is a lateral projection posterior to the orbit, which in Ventastega is formed by the lateral corner of the intertemporal bone; we infer, from the presence of an identical projection in Tiktaalik, that an intertemporal may also be present in that genus. These results corroborate the hypothesis that the remodelling of the dermal skull across the fish-tetrapod transition was gradual ${ }^{23}$. The dermal skull morphology of Tiktaalik is closer to Ventastega than to the less crownward elpistostegid Panderichthys ${ }^{24}$. Ventastega differs from Tiktaalik principally in having a smaller skull table, wider spiracles and larger eyes.

As regards the dermal bone pattern of the skull (Fig. 3b-d), Ventastega resembles Acanthostega and Ichthyostega in retaining a preopercular bone in the cheek, but differs in possessing an intertemporal bone $\mathrm{e}^{3,8}$. Other features are shared with Acanthostega but not Ichthyostega: these include a pair of median rostrals (also present in Elpistostege $e^{23}$ ) rather than a single bone, paired postparietals, and midline separation of the nasals. The last feature is associated in Ventastega with a large internasal fontanelle (Fig. 3c) which forms part of a trough-shaped midline depression in the snout. In Acanthostega there is only a narrow slit between the nasals and the trough is correspondingly smaller ${ }^{8}$. A possibly homologous small interpremaxillary fontanelle is present in several Carboniferous forms such as Crassigyrinus ${ }^{25}$ and colosteids (J.A.C. personal observation) but it is unambiguously absent in Ichthyostega ${ }^{3}$. The presence of a fontanelle in Ventastega is clearly derived in the sense that less 


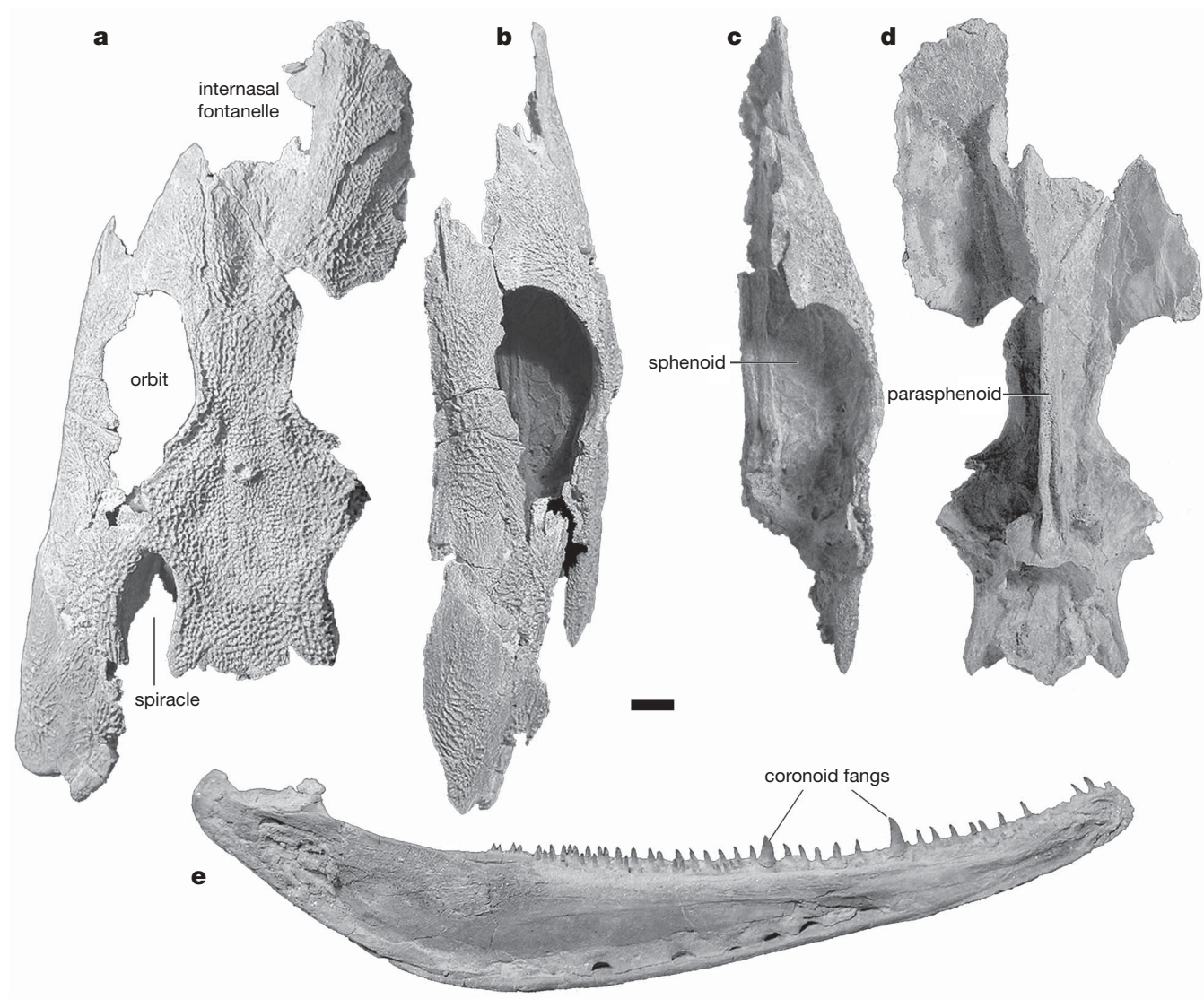

Figure 1 Cranial material of Ventastega. a, b, Associated skull roof (LDM G 81/775) and cheek (LDM G 81/776) in dorsal (a) and left lateral (b) views, anterior at the top. The internasal fontanelle, orbit and spiracle are indicated in a. c, d, The same specimen without the cheek in left lateral (c) and ventral (d) views, anterior at the top, showing the three-dimensionally preserved

braincase. The parasphenoid and sphenoid are indicated. e, Complete lower jaw (LDM G 81/777) in medial view with coronoid fangs shown. Scale bar, $10 \mathrm{~mm}$. 'LDM G' denotes the geology collections of Latvijas Dabas Muzejs, the Natural History Museum of Latvia. For other cranial material see ref. 21.

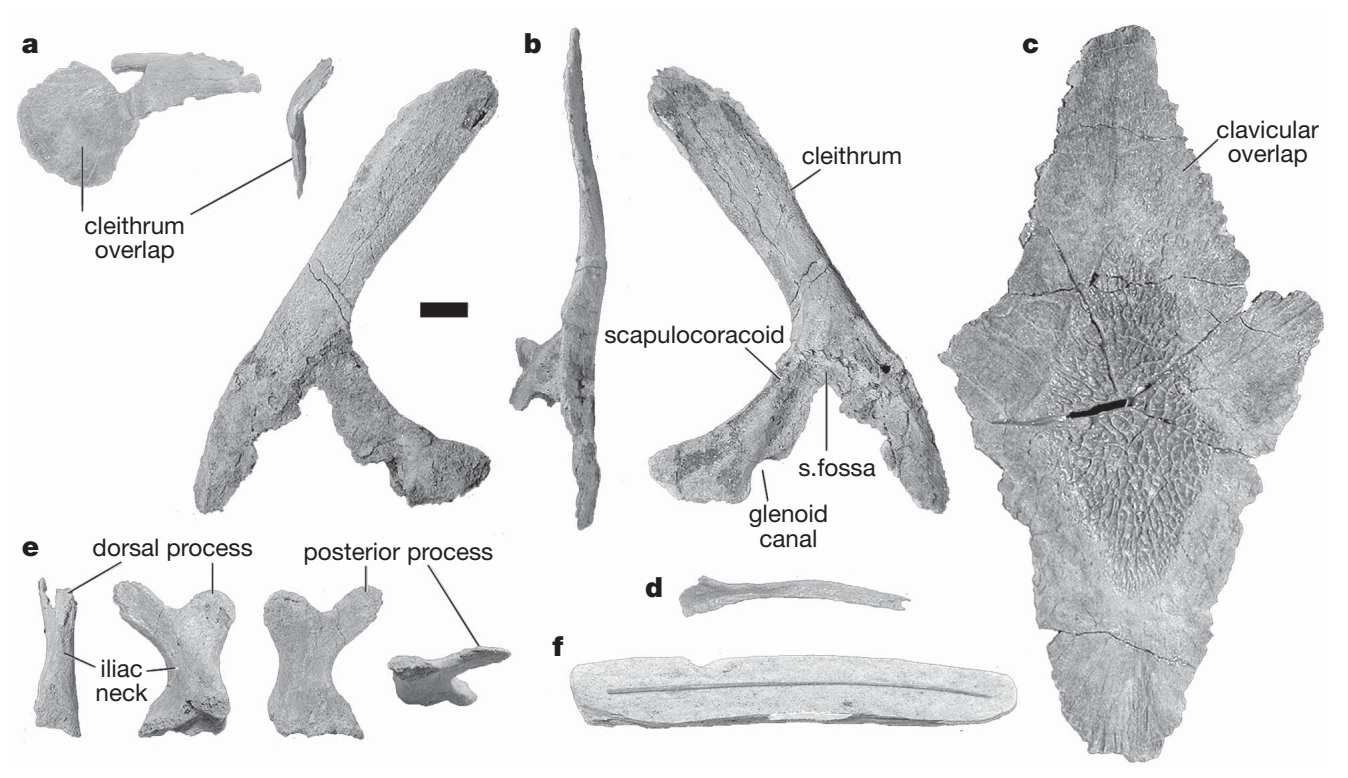

Figure 2 Postcranial material of Ventastega. a, Right anocleithrum (LDM G 81/778) in lateral and anterior views (from left to right), showing overlap for cleithrum. b, Left cleithrum (LDM G 81/779) and partial scapulocoracoid in lateral, anterior and mesial views (from left to right). Note the broad shallow subscapular fossa (s.fossa) and the partially preserved glenoid canal. c, Interclavicle (LDM G 81/601) in ventral view showing clavicular overlaps. d, A probable tetrapod rib (LDM G 81/781). e, Right ilium (LDM G 81/780) in anterior, lateral, mesial and dorsal views (from left to right), showing the iliac neck, dorsal process and posterior process. f, A probable tetrapod caudal fin lepidotrichium (LDM G 81/782) on a block of matrix. Scale bar, $10 \mathrm{~mm}$; all specimens shown to same scale. For other postcranial material see ref. 21. 
crownward taxa like Tiktaalik, Panderichthys and tristichopterids have unbroken dermal skull roofs, but the nasal bones of these forms are separated in the midline by postrostral bone $(s)^{23,24}$. It is thus possible that the absence of nasal-nasal contact in Ventastega and Acanthostega is primitive, with the fontanelle resulting directly from the loss of the postrostral bones. Another unique skull character of Ventastega is the size of the spiracular notch, which is substantially larger than those of both elpistostegids $s^{22,26,27}$ and known Devonian tetrapods $s^{3,8}$. A lamina extending down from the dorsal margin of the squamosal forms part of the lateral wall of this notch. The posterior ramus of the pterygoid is narrow as in Acanthostega, indicating the same type of spiracular architecture ${ }^{21,27}$. The increase in size of the spiracular opening across the transition has been interpreted to indicate increased reliance on air-breathing among the tetrapod stem members ${ }^{27-29}$.

The exceptionally preserved, three-dimensional braincase of Ventastega comprises a sphenoid and prootic region together with the dorsal part of the opisthotic (Fig. 5). The roof of the cranial cavity, spaces for the anterior and posterior semicircular canals, and endolymphatic ducts can be seen in ventral view. The basioccipitalexoccipital complex is missing, and the ethmoid region is unossified as in other early tetrapods. In most regards the braincase closely resembles that of Acanthostega $a^{7}$ the shape of the prootic region and its relationship to the ventral cranial fissure and the fenestra vestibuli are almost identical, as are the basipterygoid processes and the laterally open post-temporal fossae. A minor change in interpretation concerns a large and (in Ventastega) bi-lobed nerve foramen on the anterior face of the prootic; this was interpreted as transmitting nerve VII in Acanthostega ${ }^{7}$, but its large size, position on the anterior face of the otoccipital, and bilobed shape all suggest that it is actually the opening for nerve V. The presence of a fenestra vestibuli and absence of a lateral commissure suggest that the dorsal-most element of the hyoid arch was a stapes, rather than a hyomandibula as seen in Panderichthys $s^{24,27,30}$ and Tiktaalik ${ }^{22}$. Compared to the overall similarity between Ventastega and Acanthostega, the otoccipital region of Ichthyostega is very distinctive and evidently autapomorphic ${ }^{4}$.

The one area where the braincase of Ventastega differs notably from that of Acanthostega is the orbito-temporal region immediately dorsal to the basipterygoid processes (Fig. 5b). Here, Acanthostega has a fairly large interorbital foramen comparable to that in many other early tetrapods ${ }^{7}$, but Ventastega has a solid interorbital wall pierced only by small foramina for the pituitary vein and carotid artery, as in Panderichthys or 'osteolepiform' fishes-less crownward members of the tetrapod stem group ${ }^{30-32}$. Ventastega also has an anterodorsally directed tract for the optic nerve (II) with an oblique anteriorly facing opening, virtually identical to that in Panderichthys. Ventastega is more primitive than Acanthostega in regard to these characters; unfortunately we lack comparable information for Ichthyostega.

Although the braincase of Tiktaalik has not yet been described in detail, the published figures show a basicranial fenestra and a posteriorly
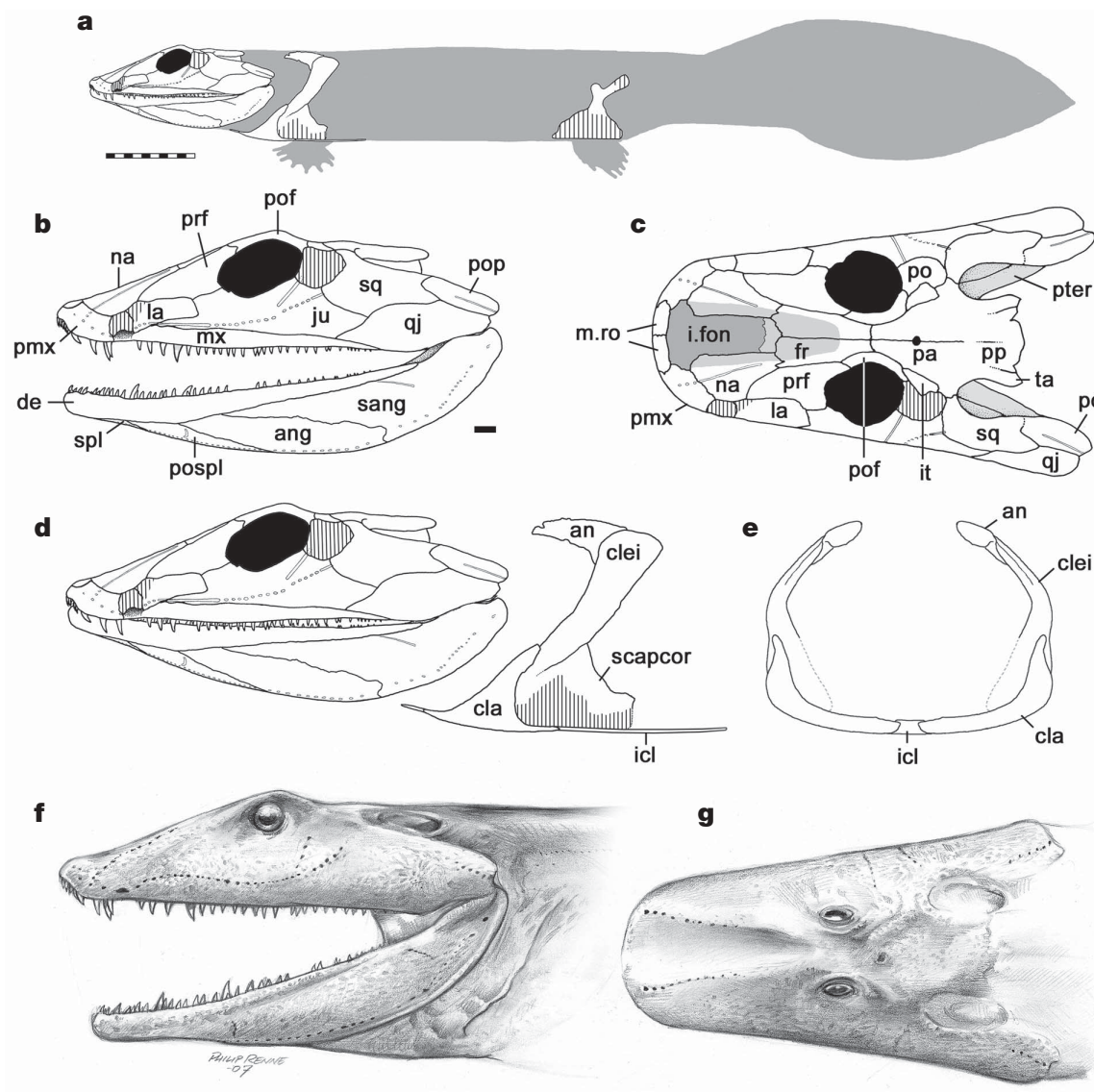

Figure 3 Reconstructions of Ventastega. a, Whole-body reconstruction showing known skeletal elements on a body outline based on Acanthostega (modified from ref. 5; original Acanthostega body reconstruction by M. I. Coates). Scale bar, $10 \mathrm{~cm} . \mathbf{b}, \mathbf{c}$, Skull reconstruction in lateral and dorsal views, based on material presented here and described previously ${ }^{21}$. d, Reconstructed association of skull and shoulder girdle in lateral view. e, Shoulder girdle in anterior view. Curvature of cleithrum based on LDM G $81 / 522$ (ref. 21). Unknown bones are indicated with vertical hatching. Scale bar for b-e, $10 \mathrm{~mm}$. f, $\mathbf{g}$, Life reconstructions of head in lateral and dorsal views (copyright $P$. Renne, 2007). an, anocleithrum; ang, angular; cla, clavicle; clei, cleithrum; de, dentary; fr, frontal; icl, interclavicle; i.fon, internasal fontanelle; it, intertemporal; ju, jugal; la, lacrimal; mx, maxilla; m.ro, median rostral; na, nasal; pa, parietal; pmx, premaxilla; po, postorbital; pof, postfrontal; pop, preopercular; pospl, postsplenial; pp, postparietal; prf, prefrontal; pter, pterygoid; qj, quadratojugal; sang, surangular; scapcor, scapulocoracoid; spl, splenial; sq, squamosal; ta, tabular. 


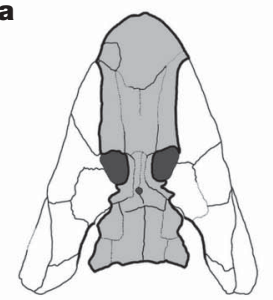

Tiktaalik

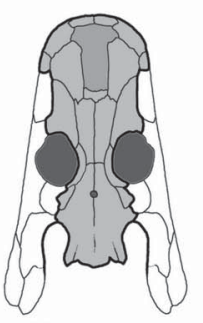

Ventastega

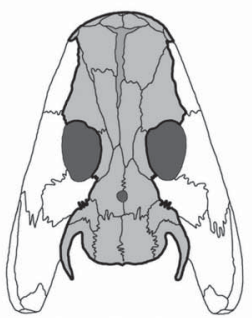

Acanthostega

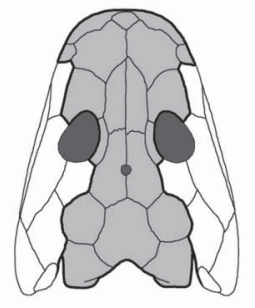

Ichthyostega

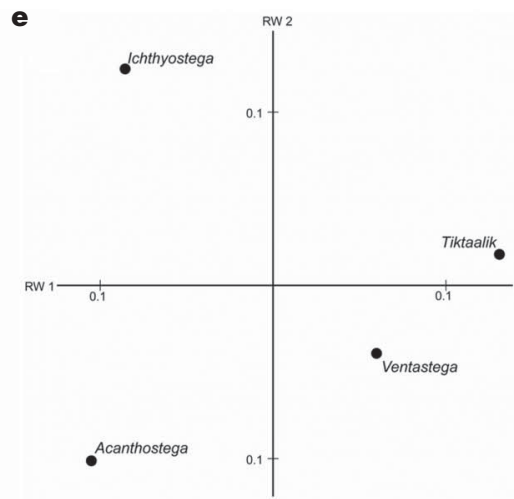

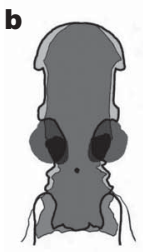

c

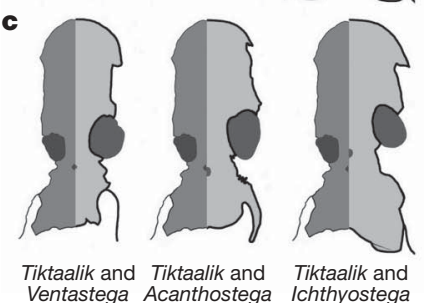

d

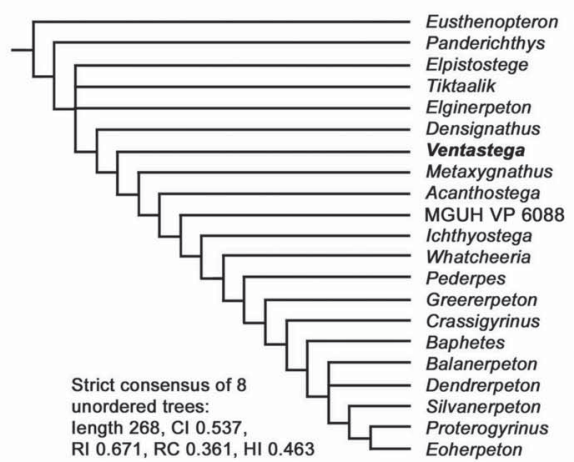

$\mathbf{f}$

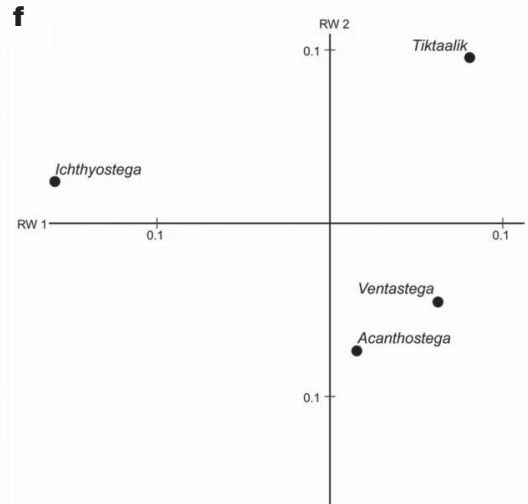

Figure 4 | Skull shape and phylogeny. a, Skulls of Tiktaalik, Ventastega, Acanthostega and Ichthyostega in dorsal view, showing the skull roof (grey) used in the morphometric comparison. In Ventastega and Acanthostega the internasal fontanelle is shown darker grey. Not drawn to scale.

b, c, Comparison of the skull roofs of Tiktaalik and Ventastega (left), Tiktaalik and Acanthostega (centre) and Tiktaalik and Ichthyostega (right). The skull roofs are overlaid in b; a left half-roof of Tiktaalik is compared to a right half-roof of Ventastega, Acanthostega or Ichthyostega in c. Tiktaalik is shown in darker grey than the tetrapods. A slight distortion of Tiktaalik has been corrected using the 'skew' command in Photoshop (b, c). d, Strict

positioned lateral commissure supporting a hyomandibula ${ }^{22}$. These features compare closely with Panderichthys ${ }^{30}$, probably indicating a broadly similar morphology - a 'lobe-fin' otoccipital comparable at consensus unordered phylogeny of tetrapodomorph fishes and early tetrapods based on 117 characters scored for 21 taxa. For further phylogenies see Supplementary Information 3. 'MGUH VP 6088' is an undescribed Famennian tetrapod from Greenland. CI, consistency index; HI, homoplasy index; RC, rescaled consistency index; RI, retention index. e, f, Relative warp analyses of skull roof outlines shown in a-c; including (e) and excluding (f) the tabular horn of Acanthostega. The first relative warp (RW) is on the horizontal axis; the second relative warp is on the vertical axis. For a full discussion of the relative warp analysis see Supplementary Information 2.

least in its ventral parts to Eusthenopteron ${ }^{31}$ or Gogonasus ${ }^{32}$ but different from the tetrapod pattern. Tiktaalikalso retains pterygoid separation by the parasphenoid and an osteolepiform lower jaw structure, whereas
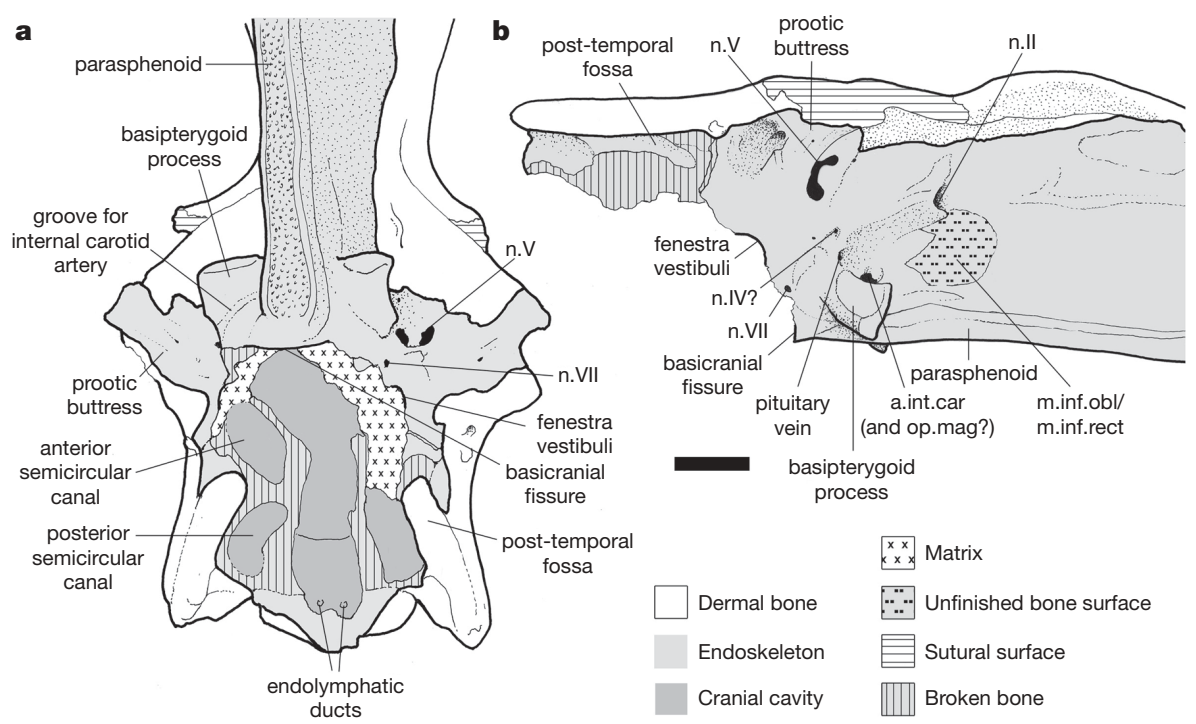

Figure 5 | Braincase of Ventastega. a, b, Posterior half of braincase plus skull roof of LDM G 81/775 in ventral and lateral views. a.int.car, foramen for the internal carotid artery; m.inf.obl/m.inf.rect, muscle scar for the inferior obliquus and/or inferior rectus eye muscles; n.II-n.VII, cranial nerves II, IV, V and VII; op.mag, ophthalmica magna artery. Scale bar, $10 \mathrm{~mm}$. 
Ventastega has pterygoid-pterygoid contact and a tetrapod lower jaw albeit with coronoid fangs ${ }^{19,21,22}$.

\section{The postcranial skeleton}

The preserved pectoral girdle of Ventastega comprises interclavicle, clavicle, cleithrum, scapulocoracoid and anocleithrum (Figs 2 and $3 \mathrm{~d}, \mathrm{e})$; the cleithrum was previously misidentified as an ilium ${ }^{21}$, but a real ilium has since been collected and the discovery of a cleithrum with attached scapulocoracoid confirms its identity. Of these elements the interclavicle, clavicle and anocleithrum resemble those of Acanthostega ${ }^{6}$ rather than Ichthyostega. The cleithrum of Ventastega is similar in outline to those of Ichthyostega and Acanthostega, and like them it lacks ornament, but in contrast to Acanthostega it lacks a postbranchial lamina. Such a lamina is also absent in Tiktaalik ${ }^{33}$, suggesting that its presence in Acanthostega may not be primitive as originally supposed ${ }^{34}$. The scapulocoracoid of Ventastega is incomplete (Fig. 2b), but enough is preserved to show that it is essentially Acanthostega-like with a broad shallow subscapular fossa ${ }^{6}$. In Ichthyostega ${ }^{3}$, Hynerpeton $^{14}$ and the girdles attributed to Elginerpeton ${ }^{13}$, the subscapular fossa is deeper with a more acute apex. A large, posteriorly positioned, partly preserved foramen in the scapulocoracoid of Ventastega may correspond to the 'glenoid canal' of Ichthyostega ${ }^{3}$ and foramina 'D' and 'E' (or possibly 'A') of Acanthostega ${ }^{6}$. There is no trace of a coracoid foramen similar to that in Tiktaalik ${ }^{33}$. As in all Devonian tetrapods except Tulerpeton ${ }^{11}$, a scapular blade is absent. Overall, the pectoral girdle of Ventastega is clearly of tetrapod grade, quite different from those of Panderichthys ${ }^{35}$ and Tiktaalik, and we infer that it bore limbs with digits.

An incomplete right ilium of Ventastega (Fig. 2e) also shows an Acanthostega-like morphology ${ }^{6}$ : the slender iliac neck-which lacks an iliac canal-branches into a distinct dorsal process with an unfinished dorsal surface and a posterodorsally directed posterior process with an upright oval cross-section. In Ichthyostega, by contrast, the robust iliac neck is pierced by a canal, the dorsal process is broader and less distinct, and the posterior process is horizontal ${ }^{3}$. These characters also occur in the ilia attributed to Elginerpeton ${ }^{13}$. In addition to these unambiguous stem tetrapod bones, Pavāri also yields numerous slender unjointed lepidotrichia, $70 \mathrm{~mm}$ or more in length (Fig. 2f), which we tentatively interpret as caudal lepidotrichia of Ventastega because of their similarity to those of Acanthostega $^{6}$. A single slender Acanthostega-like rib (Fig. 2d) may also belong to Ventastega. The strongly Acanthostega-like character of the postcranial bones, coupled with the evidence for a large caudal fin, suggest that the overall body morphology of Ventastega resembled Acanthostega. We have accordingly used a reconstructed body outline of Acanthostega ${ }^{5}$, originally based on the work of M. I. Coates, as the basis for a tentative reconstruction of Ventastega (Fig. 3a).

\section{Ventastega and the origin of tetrapods}

Although Ventastega is one of the youngest Devonian tetrapods, deriving from the late Famennian, it occupies a relatively deep position in the tetrapod stem group. All permutations of our phylogenetic analysis (Fig. 4d and Supplementary Information 3) place it below both Ichthyostega and Acanthostega; only Elginerpeton consistently occupies a more basal position. The postcranial elements attributed to Elginerpeton show that vertebrates with limbs had originated before the end of the Frasnian ${ }^{13}$. The recent redating of Metaxygnathus as late Frasnian ${ }^{36}$, in conjunction with the phylogenetic topologies recovered by our analysis, implies not only that Ventastega represents a lineage of Frasnian origin but that a substantial part of the Devonian tetrapod radiation occurred during the Frasnian. This is consistent with the occurrence of Livoniana, a fragmentary taxon apparently more derived than Tiktaalik, in the latest Givetian of the Baltic region ${ }^{37}$. It seems that the Famennian tetrapod record has only a poor stratophylogenetic fit, a contention that is further supported by the co-occurrence of the very primitive humerus ANSP 21350 (ref. 38) and much more derived whatcheeriid-like skull elements (J.A.C. personal observation) in the upper Famennian Catskill Formation of Pennsylvania.

Overall, the character combination shown by Ventastega carries a clear signal: with the exception of some possible autapomorphies, all its character states match either Acanthostega or the elpistostegids Elpistostege, Tiktaalik and Panderichthys. No characters are shared uniquely with Ichthyostega or with the cranial and attributed postcranial material of Elginerpeton. Among the less complete tetrapod stem-group members, Metaxygnathus and Densignathus have lower jaws rather similar to Ventastega, but their general morphology is unknown ${ }^{15,19,20}$. This pattern suggests that the shared VentastegaAcanthostega character complex is paraphyletically distributed through a segment of the tetrapod stem group rather than being synapomorphies of a clade. Consistent with this interpretation is the fact that certain aspects of the character complex, for example, the shape of the otic capsule and ilium, also occur in much later and more derived tetrapods such as anthracosaurs ${ }^{39,40}$ and Crassigyrinus $^{41}$. We interpret these as persistent primitive traits rather than homoplastic reversals in the latter taxa. The morphometric similarities between Ventastega and Tiktaalik, in particular the conservation of landmarks around the skull table, suggest that the changes in skull shape during this part of the fish-tetrapod transition were substantially proportional: the eyes and spiracles grew larger, the skull table smaller, and the snout broader. This contrasts with marked pattern changes in the dermal bones of the cheek, skull roof and palate, and with a restructuring of braincase that resulted in the loss of the intracranial joint, basicranial fenestra and lateral commissure as well as a host of other smaller changes. With a few modifications such as the gradual withdrawal of the notochord and the rearward extension of the parasphenoid across the basicranial fissure, this new braincase morphology remained essentially constant up into the base of the tetrapod crown group ${ }^{42}$. Even the highly specialized braincase of Ichthyostega is recognizably derived from this pattern ${ }^{4}$. With regard to the postcranial skeleton, Ventastega consistently resembles Acanthostega; all the changes that distinguish Devonian tetrapod from elpistostegid limb girdles-loss of the supracleithrum and post-temporal; enlargement of the scapulocoracoid; loss of the coracoid foramen; enlargement of the interclavicle, creation of a sacrum-seem to have already occurred.

Because of its phylogenetic position and character complement it is tempting to interpret Ventastega as a straightforward evolutionary intermediate, which represents with reasonable accuracy the character complement of the tetrapod stem lineage at a point on the internode between Tiktaalik and Acanthostega. However, this simple picture should be approached with a degree of caution. ANSP 21350 and Elginerpeton in particular (whether or not the latter taxon is taken to include the disputed humerus GSM 104536; refs 13, 38) show character combinations that are substantively different from those of Ventastega and Acanthostega without being obviously autapomorphic, and both probably occupy deep positions in the phylogeny. At a minimum this demonstrates the presence of considerable morphological diversification among the earliest tetrapods. More importantly, however, the discovery of articulated material of these or similar forms could have a substantial impact on the tree topology. Ventastega, like Tiktaalik, conforms remarkably well to prior expectations of what a transitional form at that particular point in the phylogeny should be like; whether the same will be true of future discoveries remains to be seen.

\section{METHODS SUMMARY}

The material was excavated from Pavāri locality in 1970, 1973, 1988, 1991, 1995 and 2001 and deposited at the Natural History Museum of Latvia. In the laboratory, fossils were freed from surrounding sediment (unconsolidated sand) by mechanical preparation with a mounted needle. Relative warps analysis ${ }^{43}$ was used to quantify head-shape variation in the various Devonian tetrapods and 
elpistostegids. Landmarks were digitized from published reconstructions ${ }^{3,8,22,24}$ using the program tpsDig v. 1.40 (ref. 44). Relative warps analysis was conducted in tpsRelw v. 1.39 (ref. 45). Phylogenetic analysis was performed in PAUP 4.0b10 (ref. 46) using a Branch-and-Bound search with default settings, with Eusthenopteron specified as the out-group. Life reconstructions were drawn by P. Renne under the supervision of P.E.A.

\section{Received 22 November 2007; accepted 9 April 2008.}

1. Säve-Söderbergh, G. Preliminary note on Devonian stegocephalians from East Greenland. Meddr. Grønland 94, 1-107 (1932).

2. Jarvik, E. On the fish-like tail in the ichthyostegid stegocephalians with descriptions of a new stegocephalian and a new crossopterygian from the Upper Devonian of East Greenland. Meddr. Grønland 114, 1-90 (1952).

3. Jarvik, E. The Devonian tetrapod Ichthyostega. Fossils Strata 40, 1-213 (1996).

4. Clack, J. A. et al. A uniquely specialized ear in a very early tetrapod. Nature 425, 65-69 (2003).

5. Ahlberg, P. E., Clack, J. A. \& Blom, H. The axial skeleton of the Devonian tetrapod Ichthyostega. Nature 437, 137-140 (2005).

6. Coates, M. I. The Devonian tetrapod Acanthostega gunnari Jarvik: postcranial anatomy, basal tetrapod interrelationships and patterns of skeletal evolution. Trans. R. Soc. Edinb. Earth Sci. 87, 363-421 (1996).

7. Clack, J. A. The neurocranium of Acanthostega gunnari Jarvik and the evolution of the otic region in tetrapods. Zool. J. Linn. Soc. 122, 61-97 (1998).

8. Clack, J. A. A revised reconstruction of the dermal skull roof of Acanthostega, an early tetrapod from the Late Devonian. Trans. R. Soc. Edinb. Earth Sci. 93, 163-165 (2003).

9. Campbell, K. S. W. \& Bell, M. W. A primitive amphibian from the Late Devonian of New South Wales. Alcheringa 1, 369-381 (1977).

10. Lebedev, O. A. \& Clack, J. A. Upper Devonian tetrapods from Andreyevka, Tula Region, Russia. Palaeontology 36, 721-734 (1993).

11. Lebedev, O. A. \& Coates, M. I. The postcranial skeleton of the Devonian tetrapod Tulerpeton curtum. Zool. J. Linn. Soc. 114, 307-348 (1995).

12. Ahlberg, P. E. Elginerpeton pancheni and the earliest tetrapod clade. Nature 373, 420-425 (1995).

13. Ahlberg, P. E. Postcranial stem tetrapod remains from the Devonian of Scat Craig, Morayshire, Scotland. Zool. J. Linn. Soc. 122, 99-141 (1998).

14. Daeschler, E. B., Shubin, N. H., Thomson, K. S. \& Amaral, W. W. A Devonian tetrapod from North America. Science 265, 639-642 (1994).

15. Daeschler, E. B. Early tetrapod jaws from the Late Devonian of Pennsylvania, USA. J. Paleontol. 74, 301-308 (2000)

16. Zhu, M., Ahlberg, P. E., Zhao, W. \& Jia, L. First Devonian tetrapod from Asia. Nature 420, 760-761 (2002).

17. Clement, G. et al. Devonian tetrapod from Western Europe. Nature 427, 412-413 (1994).

18. Lebedev, O. A. A new tetrapod Jakubsonia livnensis from the Early Famennian (Devonian) of Russia and palaeoecological remarks on the Late Devonian tetrapod habitats. Acta Univ. Latviensis 679, 79-98 (2004).

19. Ahlberg, P. E. \& Clack, J. A. Lower jaws, lower tetrapods - a review based on the Devonian genus Acanthostega. Trans. R. Soc. Edinb. Earth Sci. 89, 11-46 (1998).

20. Ahlberg, P. E., Friedman, M. \& Blom, H. New light on the earliest known tetrapod jaw. J. Vert. Paleontol. 25, 720-724 (2005).

21. Ahlberg, P. E., Lukševičs, E. \& Lebedev, O. The first tetrapod finds from the Devonian (Upper Famennian) of Latvia. Phil. Trans. R. Soc. B 343, 303-328 (1994).

22. Daeschler, E. B., Shubin, N. H. \& Jenkins, F. A. A Devonian tetrapod-like fish and the evolution of the tetrapod body plan. Nature 440, 757-763 (2006).

23. Schultze, H. P. \& Arsenault, M. The panderichthyid fish Elpistostege: a close relative of tetrapods? Palaeontology 28, 293-309 (1985).

24. Vorobyeva, E. I. Morphology and nature of evolution of crossopterygian fishes [In Russian]. Trudy Paleont. Inst. 163, 1-239 (1977).

25. Clack, J. A. The Scottish Carboniferous tetrapod Crassigyrinus scoticus (Lydekker) - cranial anatomy and relationships. Trans. R. Soc. Edinb. Earth Sci. 88, 127-142 (1998).
26. Vorobyeva, E. I. \& Schultze, H. P. Description and systematics of panderichthyid fishes with comments on their relationship to tetrapods. In Origins of the Higher Groups of Tetrapods (eds Schultze, H. P. \& Trueb, L.) 68-109 (Cornell, Ithaca, New York, 1991).

27. Brazeau, M. D. \& Ahlberg, P. E. Tetrapod-like middle ear architecture in a Devonian fish. Nature 439, 318-321 (2006).

28. Long, J. A., Young, G. C., Holland, T., Senden, T. J. \& Fitzgerald, E. M. G. An exceptionally preserved Devonian fish from Australia sheds light on tetrapod origins. Nature 444, 199-202 (2006).

29. Clack, J. A. Devonian climate change, breathing, and the origin of the tetrapod stem group. Integr. Comp. Biol. 47, 510-523 (2007)

30. Ahlberg, P. E., Clack, J. A. \& Lukševičs, E. Rapid braincase evolution between Panderichthys and the earliest tetrapods. Nature 381, 61-64 (1996).

31. Jarvik, E. Basic Structure and Evolution of Vertebrates Vol. 1 (Academic, London, 1980).

32. Long, J. A., Barwick, R. E. \& Campbell, K. S. W. Osteology and functional morphology of the osteolepiform fish Gogonasus andrewsae Long 1985, from the Upper Devonian Gogo Formation, Western Australia. Rec. West. Aust. Mus. 57 (Suppl.), 1-89 (1997)

33. Shubin, N. H., Daeschler, E. B. \& Jenkins, F. A. The pectoral fin of Tiktaalik rosae and the origin of the tetrapod limb. Nature 440, 764-771 (2006).

34. Coates, M. I. \& Clack, J. A. Fish-like gills and breathing in the earliest known tetrapods. Nature 352, 234-236 (1991).

35. Vorobyeva, E. I. The shoulder girdle of Panderichthys rhombolepis (Gross) (Crossopterygii), Upper Devonian, Latvia. GeoBios 28, 285-288 (1995).

36. Young, G. C. Biostratigraphic and biogeographic context for tetrapod origins during the Devonian: Australian evidence. Alcheringa 1 (Special Issue), 409-428 (2006).

37. Ahlberg, P. E., Lukševičs, E. \& Mark-Kurik, E. A near-tetrapod from the Baltic Middle Devonian. Palaeontology 43, 533-548 (2000).

38. Shubin, N. H., Daeschler, E. B. \& Coates, M. I. The early evolution of the tetrapod humerus. Science 304, 90-93 (2004).

39. Clack, J. A. Pholiderpeton scutigerum Huxley, an amphibian from the Yorkshire coal measures. Phil. Trans. R. Soc. B 318, 1-107 (1987).

40. Clack, J. A. \& Holmes, R. The braincase of the anthracosaur Archeria crassidisca, with comments on the interrelationships of primitive tetrapods. Palaeontology 31, 85-107 (1988).

41. Panchen, A. L. \& Smithson, T. R. The pelvic girdle and hind limb of Crassigyrinus scoticus (Lydekker) from the Scottish Carboniferous and the origin of the tetrapod pelvic skeleton. Trans. R. Soc. Edinb. Earth Sci. 81, 31-44 (1990).

42. Ruta, M., Coates, M. I. \& Quicke, D. L. J. Early tetrapod relationships revisited. Biol. Rev. 78, 251-345 (2003).

43. Bookstein, F. L. Morphometric tools for landmark data: geometry and biology (Cambridge Univ. Press, 1991).

44. Rohlf, F. J. tpsDig, version 1.40 (Dept. of Ecology \& Evolution, Stony Brook, New York, 2004).

45. Rohlf, F. J. tpsRelw, version 1.39 (Dept. of Ecology \& Evolution, Stony Brook, New York, 2004).

46. Swofford, D. PAUP*: Phylogenetic Analysis Using Parsimony (and other methods) 4.0 Beta (Sinauer Associates, Sunderland, Massachusetts, 2002).

Supplementary Information is linked to the online version of the paper at www.nature.com/nature.

Acknowledgements We acknowledge the hard work and dedication of the Pavāri field crews of 1988, 1991, 1995 and 2001. P.E.A. acknowledges the financial support of the Natural History Museum, London (1995 and 2001 field seasons) and the Swedish Research Council. H.B. acknowledges the support of NERC (2001 field season) and the Swedish Research Council. E.L. acknowledges the financial support of the Latvian Council of Science. Special thanks to Philip Renne for his life reconstructions.

Author Information Reprints and permissions information is available at www.nature.com/reprints. Correspondence and requests for materials should be addressed to P.E.A. (per.ahlberg@ebc.uu.se). 